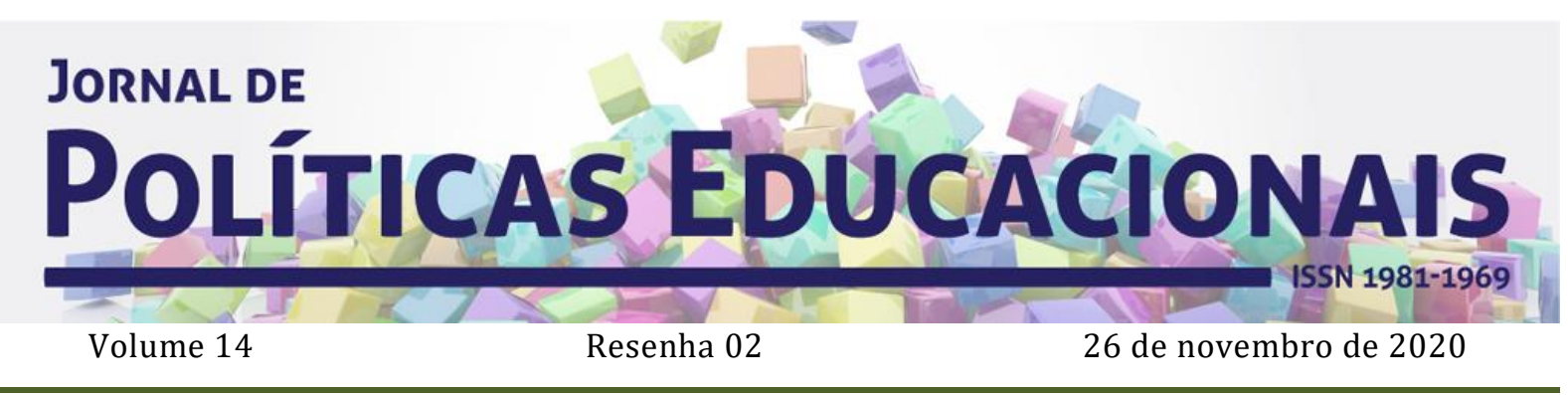

\title{
Como as corporações globais querem usar as escolas para moldar o homem para o mercado
}

MOURA, S. A. de; ANDRADE, W. M. L. L. de. Resenha da obra Como as corporações globais querem usar as escolas para moldar o homem para o mercado. Campinas, SP: Vide Editorial, 2018. Jornal de Políticas Educacionais. V. 14, r. 02. Novembro de 2020.

Sergio Andrade de Moura ${ }^{1}$ Wellingta Magnolia Lacerda Leite de Andrade ${ }^{2}$

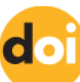

http://10.5380/ipe.v14i0.77634

O poder de influência sobre as políticas educacionais de corporações globais, como a Organização para Cooperação e Desenvolvimento Econômico (OCDE), Banco Mundial, Fórum Econômico Mundial, Fundo Monetário Internacional (FMI), bem como think tanks, como a Atlas Economic Research Foundation, tem sido objeto de pesquisas, estudos, dissertações e teses nos diversos centros de Ciências Humanas e Sociais e, sobretudo, nos Centros de Educação de inúmeras universidades. Desenvolver pesquisa nesse campo significa estudar e refletir sobre como as políticas educacionais nacionais/locais tem sido reformadas para convergirem para um parâmetro global de políticas educacionais que seguem princípios e diretrizes neoliberais e atendem aos interesses do mercado e, ou seja, como a educação foi submetida à economia.

\footnotetext{
${ }^{1}$ Doutorando do Programa de Pós-Graduação em Educação da UFPB. Participa do Grupo de Pesquisa Psicologia Educacional, formação e infância - estudos sobre classes populares e educação pública - PEFI (UFPB/PPGE). João Pessoa, PB, Brasil. Orcid: https://orcid.org/0000-0003-2665-5040 E-mail: prof.sergiomoura@gmail.com 2 Mestre em Educação UFPB/PPGE (2018). Mestre em Ciências da Educação pela Universidade Lusófona de Humanidades e Tecnologias (2005) - Lisboa - Pt. Membro do Grupo de Pesquisa em Formação Docente - UFPB/PPGE. Professora de Cursos de Pedagogia e Pós-Graduação do Centro Integrado de Tecnologia e Pesquisa - CINTEP/PB e FNSL. João Pessoa, PB, Brasil. Orcid: https://orcid.org/0000-0003-0946-1447 Email:wellingtaa@hotmail.com
} 
MOURA, S. A. de; ANDRADE, W. M. L. L. de. Resenha da obra Como as corporações globais querem usar as escolas para moldar o homem para o mercado

Propondo refletir sobre essas questões e outras inter-relacionadas, Joel Spring em sua obra analisa um longo período histórico, que parte da década de 1940, e rastreia a atuação das corporações globais no que se refere a concepção das políticas educacionais nacionais/locais e as influências das teorias econômicas concebidas na Escola de Chicago, especificamente a Teoria do Capital Humano e do Paradigma da Escolha Racional, no âmbito da educação e o processo de ecomomização e corporativização da educação e das famílias.

A obra é organizada em sete capítulos. Ao final de cada capítulo o autor, de modo didático, apresenta uma conclusão que procura sintetizar as principais questões abordadas no capítulo, faz algumas reflexões e expõe de forma resumida os pontos que serão discutidos no capítulo seguinte, procurando dessa forma estabelecer uma espécie de conexão entre as partes que compõe a obra.

No primeiro capítulo o autor procura analisar o processo por meio do qual ocorreu a submissão da educação aos parâmetros e teorias econômicas, bem como aos interesses do mercado e das grandes corporações globais. Nesse sentido, o autor faz uma análise de algumas obras dos principais economistas da Escola de Chicago, como Gary Becker, Milton Friedman, Theodore Schultz, e James Heckman, bem como do contexto histórico pós Segunda Guerra Mundial, em que ocorreu uma forte oposição ao comunismo e o fortalecimento das concepções do livre mercado como estratégia para o desenvolvimento econômico, o crescimento da renda e o combate à pobreza. Destaca-se nesse capítulo as discussões acerca da Teoria do Capital Humano e do Paradigma da Escolha Racional e suas implicações na economização da educação e das famílias, assim como no processo de promoção de um ensino que desenvolva habilidades que atendam o mercado de trabalho. Além disso, o autor faz reflexões críticas a respeito dos economistas da Escola de Chicago, sobretudo, por estes em suas obras não conseguirem demonstrar e apresentar evidências concretas da relação causal entre educação e crescimento/desenvolvimento econômico, aumento da renda e redução da pobreza, assim como por desconsiderar em suas análises e teorias os contextos sociais, políticos e históricos, bem como as suas repercussões sobre a economia.

No capítulo seguinte o autor discute o tema dos testes padronizados, sobretudo, o Programa Internacional para Avaliação de Estudantes (PISA), planejado desde a década de 1970 pela OCDE e, implementado em conjunto com os ministérios da educação de diversos países a partir do ano de 1997. O autor procurar destacar de forma crítica o papel da OCDE, classificado como o "Ministério Mundial da Educação", em transformar o PISA, um teste de cerca de 2 horas e 40 minutos, que envolve interpretação textual, matemática e ciências, em um mecanismo para medir habilidades e, consequentemente, a qualidade do capital humano de um 
MOURA, S. A. de; ANDRADE, W. M. L. L. de. Resenha da obra Como as corporações globais querem usar as escolas para moldar o homem para o mercado

país, bem como para fazer previsões questionáveis sobre o futuro das economias nacionais. Segundo o autor, a OCDE e os seus testes padronizados estimularam um processo de competição global entre as nações para desenvolver as habilidades requeridas pelo mercado. Além disso, o autor procura discutir que o crescente poder de influência da OCDE e dos seus testes têm contribuindo para um processo de padronização dos sistemas de educação e para construção de uma cultura mundial de ensino que converge com os objetivos de economização da educação.

No terceiro capítulo o autor desenvolve a discussão de como as habilidades relacionadas ao mercado/ambiente de trabalho foram transformadas na "nova moeda global". O autor procura apresentar como a OCDE, o Banco Mundial e o Fórum Econômico Mundial estão empenhados em influenciar na construção de currículos em que os conhecimentos são secundários, tornam-se apenas um meio para o aprendizado/desenvolvimento de habilidades, principalmente, as habilidades técnicas (como proficiência na língua materna e matemática) e interpessoais (como as capacidades de trabalhar em equipe, de tomar decisões, de resolver problemas, de planejar e organizar, e de se comunicar com outras pessoas). Na obra, o autor, procura demonstrar que esse modelo de currículo baseado em habilidades atende aos interesses das corporações e transforma a educação numa espécie de "apêndice da economia". Nesse ponto, desenvolve-se as críticas a tais modelos de currículo que priorizam, sobretudo, conhecimentos em letramento e matemática e, ignoram ou não contemplam questões, como justiça social, direitos humanos, meio ambiente e desenvolvimento da consciência cidadã, ética e do censo crítico para compreender os contextos políticos, econômicos e sociais e para defender seus direitos frente ao poder público e as corporações, criando, dessa forma, uma espécie de "trabalhador conformado".

O quarto capítulo envolve a discussão da ação do Banco Mundial no processo de economização da educação na medida em que planeja e implementa ações desenvolvimentistas nos países pobres. A história do Banco Mundial, segundo o autor, apresentou diversos períodos de evolução em suas políticas. No primeiro momento, a sua atuação era centrada em realizar empréstimos para projetos de infraestrutura. Depois, o seu foco concentrou-se nas ações de combate à pobreza. Em seguida, as suas políticas estiveram fortemente influenciadas pelo neoliberalismo. Por fim, entrou no quarto período, denominado de "neoliberal verde", que é marcado por preocupações com o meio ambiente. Segundo Spring o Banco Mundial possui uma perspectiva singular em relação à educação que ultrapassar a perspectiva de formação de uma mão de obra com habilidades que atendam aos interesses do mercado e que promovam o crescimento econômico. Estão incluídas também em suas perspectivas de educação a 
MOURA, S. A. de; ANDRADE, W. M. L. L. de. Resenha da obra Como as corporações globais querem usar as escolas para moldar o homem para o mercado

preocupação com o bem-estar geral dos países, a qualidade de vida e o meio ambiente. Nesse capítulo o autor traça o panorama de como os economistas do Banco Mundial passam a defender uma educação que forneça maior autonomia para os pobres, para que estes passem a pressionar o poder público por serviços mais justos e pela adoção de políticas governamentais que favoreçam o livre mercado, que contribua para que os trabalhadores possam estar aptos para se adaptarem as mudanças no mercado, que colabore para o desenvolvimento sustentável e para a coesão social. $O$ autor expõe que o Banco Mundial defende a perspectiva que o conhecimento se encontra no mesmo patamar que o capital, ou seja, o conhecimento passa a ser considerado um valor econômico. Nesse sentido, para o Banco Mundial a educação é um ativo para combater a pobreza.

O cerne do quinto capítulo são as discussões sobre o Fórum Econômico Mundial. Neste capítulo, o autor explica que o Fórum Econômico Mundial buscou construir parcerias multilaterais, envolvendo empresas, governos e sociedade civil, para influenciar as políticas educacionais, difundir a concepção da Teoria do Capital e uma educação para o empreendedorismo nas escolas de nível secundário e superior. $\mathrm{O}$ autor busca explicar como essas parcerias multilaterais beneficiaram duplamente as corporações: primeiro, ao conseguir trabalhadores com as habilidades desejadas; e, em segundo lugar, ao produzir um mercado na educação para os seus produtos e serviços oferecidos pelas empresas. Nesse sentido, o autor aponta que as corporações devem estar envolvidas no processo de construção das políticas educacionais e dos currículos escolares. Além disso, o autor procura destacar que o Fórum Econômico Mundial defende um Modelo de Planejamento Educacional apoiado na Teoria da Governança Multilateral e, adentra nas discussões de como o Fórum Econômico Mundial classifica os países e avalia o seu capital humano usando o seu Índice de Capital Humano que emprega além dos testes internacionais, como o PISA, TIMSS e PIRLS, quatro pilares: educação; saúde/bem-estar; força de trabalho/emprego; ambiente favorável.

No sexto capítulo o autor embrenhar-se nas discussões da família uniformizada ideal e na criação da personalidade corporativa propostas pelos expoentes da Escola de Chicago. Nesse sentido, discute-se a economização da família a partir da perspectiva dos trabalhos de James Colleman, Gary Becker e James Heckman. Esses teóricos, segundo o autor, buscaram traçar um modelo de família ideal, comprometida com a educação infantil, economicamente eficiente para garantir um capital social adequado para a formação de bons trabalhadores, isto é, homens e mulheres que possuíssem as habilidades interpessoais necessárias para serem bem-sucedidos em alcançar o sucesso econômico pessoal, bem como que contribuíssem para o aumento da produtividade e para o crescimento dos mercados. Nos casos em que as famílias não possuem 
MOURA, S. A. de; ANDRADE, W. M. L. L. de. Resenha da obra Como as corporações globais querem usar as escolas para moldar o homem para o mercado

o capital social necessário para alcançar esses objetivos, caberia a educação infantil compensar tais deficiências nas crianças. Segundo Spring, os membros da Escola de Chicago argumentam que os investimentos públicos na educação infantil são os que apresentam os melhores retornos para à sociedade. Assim, defendem que as políticas públicas destinem uma maior atenção e investimentos para pré-escola, sobretudo, para as crianças originárias de famílias de baixa renda, pois ela é fundamental para o desenvolvimento do capital humano.

No sétimo e último capítulo, o autor faz uma espécie de síntese das discussões realizadas ao longo da obra. Nesse sentido, destaca que no período do pós Segunda Guerra Mundial, no contexto da Guerra Fria, foram elaboradas teorias econômicas, como a Teoria do Capital Humano e Teoria da Escolha Racional, na Escola de Chicago/EUA, que influenciaram na construção de um modelo de educação que atendesse as necessidades e interesses das corporações. Além disso, destaca o autor, que foram constituídas organizações globais, como a OCDE, Banco Mundial e Fórum Econômico Mundial, que desempenharam um papel importante na defesa e propagação das ideias e concepções das supracitadas teorias e de um modelo de educação centrado no ensino de habilidades técnicas e interpessoais exigidas pelo mercado. É apresentado, ainda, as estratégias próprias e específicas que cada uma dessas organizações desenvolveu para alcançar esse objetivo comum. Tudo isso contribuiu enormemente para a economização da educação. Sobre isso, o autor, apresenta sua concepção de que todo o processo não foi resultado de uma conspiração global, todavia, uma espécie de confluência de concepções/ideias e interesses de diversos atores políticos e corporativos/empresariais. A concepção propagada de educação era tentadora e atraente para governos e corporações: investir num certo padrão de educação produziria crescimento econômico, aumentaria a renda e combateria a pobreza e as desigualdades sociais. Por fim, o autor apresenta sua crítica ao modelo de educação fundamentado em desenvolver habilidades técnicas e interpessoais. Nesse sentido, ressalta que entre as habilidades ensinadas nesse padrão de educação estão ausentes habilidades, como compaixão, altruísmo e empatia, que são importantes na promoção da justiça social.

Joel Spring, pesquisador norte-americano, estuda e escreve na área de política educacional. Sua perspicácia teórica e crítica permitiu produzir uma obra valiosa que analisa, em um vasto recorte temporal, o papel desempenhado por poderosas organizações globais em promover a economização da educação, bem como um modelo de educação centralizado no ensino de habilidades técnicas e interpessoais para atender as necessidades do mercado. Desta forma, recomenda-se essa obra aos profissionais e pesquisadores das áreas de Educação e 
MOURA, S. A. de; ANDRADE, W. M. L. L. de. Resenha da obra Como as corporações globais querem usar as escolas para moldar o homem para o mercado

Ciências Sociais, sobretudo, aqueles que se ocupam em estudar as políticas educacionais, bem como para todos que desejam compreender, discutir e refletir sobre essa importante temática. 

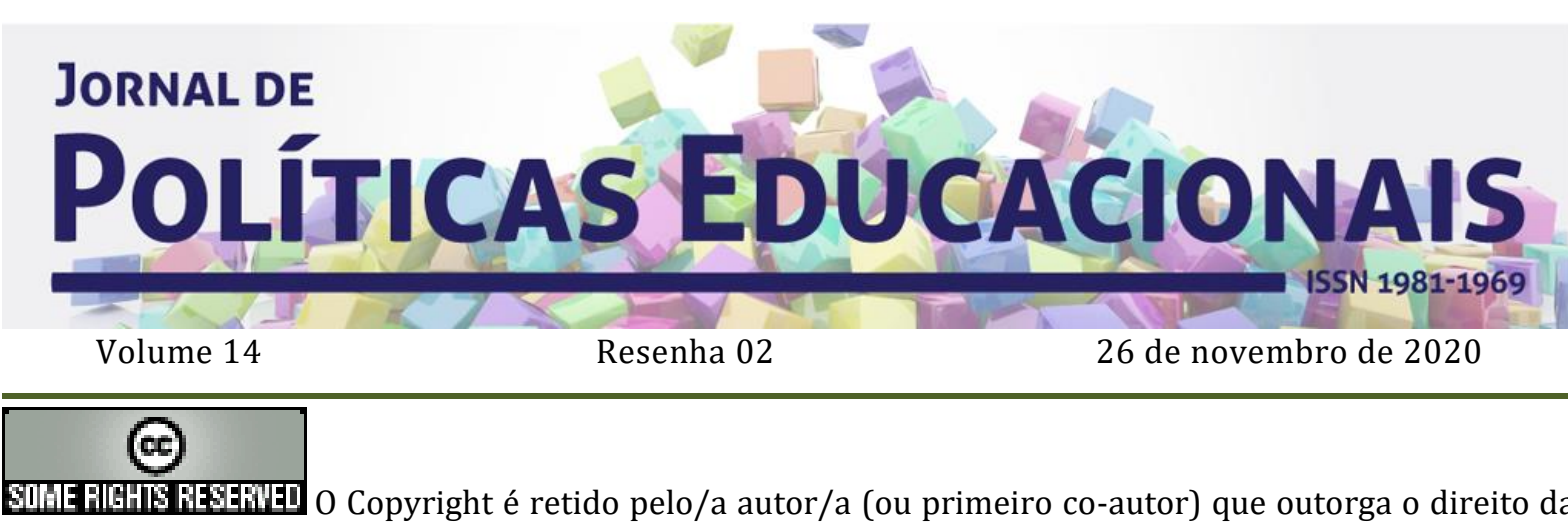

Jicho pelo/a autor/a (ou pr primeira publicação ao Jornal de Políticas Educacionais. Mais informação da licença de Creative Commons encontram-se em http://creativecommons.org/licenses/by-nc-nd/2.5. Qualquer outro uso deve ser aprovado em conjunto pelo/s autor/es e pelo periódico.

JoRNAL DE POLÍTICAS EDUCACIONAIS é uma publicação do Núcleo de Políticas Educacionais do Setor de Educação da Universidade Federal do Paraná - NuPE/UFPR, em consórcio com a Linha de Pesquisa em Políticas Educacionais do Programa de Pós-Graduação em Educação - PPGE/UFPR, que aceita colaboração, reservando-se o direito de publicar ou não o material espontaneamente enviado à redação. As colaborações devem ser enviadas ao NuPE/UFPR, conforme orientações contidas nas páginas do periódico na internet: http://revistas.ufpr.br/ipe.

Indexação:

BBE - Biblioteca Brasileira de Educação (MEC/INEP)

Clase (Base de Datos Bibliográfica de Revistas de Ciencias Sociales y Humanidades) Diadorim - Diretório de Política de Acesso Aberto das Revistas Científicas Brasileiras (IBICT) Google Scholar Index Copernicus Portal de Periódicos (CAPES)

SER - Sistema Eletrônico de Revistas da Universidade Federal do Paraná (SER/UFPR) Sumários de Revistas Brasileiras (FUNPEC-RP) DRJI - Directory of Research Journals Indexing

(Periódico integralmente disponível apenas em via eletrônica)

Jornal de Políticas Educacionais / Núcleo de Políticas Educacionais da Universidade Federal do Paraná NuPE/UFPR - v.1, n. 1 (1o semestre de 2007) - Curitiba: NuPE/UFPR.

Volume 14, resenha 02 - Novembro de 2020

ISSN 1981-1969

1. Educação - Periódicos. 2. Política Educacional - Periódicos. I. NuPE/UFPR

Comitê Editorial:

Elisângela Scaff (UFPR)

Daniela de Oliveira Pires (UFPR)

Conselho Editorial:

Andréa Barbosa Gouveia (UFPR - Brasil), Cesar Tello (Universidad Nacional Tres Febrero, Argentina), Fernanda Saforcada (Universidad de Buenos Aires - UBA - Argentina), Gladys Beatriz Barreyro (USP Brasil), Gustavo Enrique Fischman, (Arizona State University - USA), Jefferson Mainardes (UEPG - Brasil), João Ferreira de Oliveira (UFG - Brasil), Juca Gil (UFRGS - Brasil), Luiz Souza Júnior (UFPB - Brasil), Ney 
MOURA, S. A. de; ANDRADE, W. M. L. L. de. Resenha da obra Como as corporações globais querem usar as escolas para moldar o homem para o mercado

Cristina Monteiro de Oliveira (UFPA - Brasil), Nicolás Bentancur, (Universidad de la República de Uruguay), Robert Verhine (UFBA - Brasil), Rosana Cruz (UFPI - Brasil), Rubens Barbosa Camargo (USP - Brasil), Sebastián Donoso Díaz (Universidad de Talca - Chile), TheresaAdrião (UNICAMP - Brasil), Vera Peroni (UFRGS - Brasil).

Créditos e Agradecimentos:

Revisão de Língua Portuguesa, Abstract e Resumen: PROGRAMA DE APOIO ÀS PUBLICAÇõES CIENTÍFICAS PERIÓDICAS DA UFPR

Arte e diagramação: TIAGO TAVARES (thiagotav@gmail.com)

Jornal de Políticas Educacionais

Universidade Federal do Paraná

Setor de Educação

Núcleo de Políticas Educacionais - NuPE/UFPR

Avenida Sete de Setembro, 2645

2 o andar, Sala 213

80.230-010 - Curitiba - PR - Brasil

Tel.: 41-3535-6264

jpe@ufpr.br

http://revistas.ufpr.br/jpe 